\title{
Bonding constraint-induced defect formation at Si-dielectric interfaces and internal interfaces in dual-layer gate dielectrics
}

\author{
G. Lucovsky a) \\ Department of Physics, North Carolina State University, Raleigh, North Carolina 27695-8202 \\ Y. Wu \\ Department of Electrical and Computer Engineering, North Carolina State University, Raleigh, \\ North Carolina 27695-8202 \\ H. Niimi \\ Department of Materials Science and Engineering, North Carolina State University, Raleigh, \\ North Carolina 27695-8202 \\ V. Misra \\ Department of Electrical and Computer Engineering, North Carolina State University, Raleigh, \\ North Carolina 27695-8202 \\ J. C. Phillips \\ Lucent Bell Laboratories, Murray Hill, New Jersey 07974
}

(Received 19 January 1999; accepted 30 March 1999)

\begin{abstract}
As aggressive scaling of integrated circuits continues into the next century, insulators with dielectric constants higher than $\mathrm{SiO}_{2}$ with different local bonding arrangements will be required to increase gate dielectric capacitance in field effect transistor devices. An important issue in semiconductor device physics is determining whether differences between the bonding at (i) $\mathrm{Si}-\mathrm{SiO}_{2}$ interfaces and (ii) interfaces between crystalline $\mathrm{Si}$ and alternative gate dielectric materials will result in increased densities of electrically active defects at the alternative dielectric interfaces, thereby limiting targeted levels of performance and reliability. In particular, it is important to understand from a chemical bonding perspective why $\mathrm{Si}-\mathrm{SiO}_{2}$ interfaces display both low defect densities and high reliability, while other interfaces such as $\mathrm{Si}-\mathrm{Si}_{3} \mathrm{~N}_{4}$ with similar bonding chemistry, display defect densities that are at least two orders of magnitude higher. Building on previously established criteria for formation of low defect density glasses and thin films, constraint theory is extended to crystalline $\mathrm{Si}$-dielectric interfaces that go beyond $\mathrm{Si}-\mathrm{SiO}_{2}$ through development of a model that is based on the average bonding coordination at these interfaces. This approach identifies quantitative bonding criteria that distinguish between device-quality and highly defective interfaces. This extension of constraint theory is validated by its application to interfaces between $\mathrm{Si}$ and stacked silicon oxide/ nitride dielectrics which demonstrates that as in bulk glasses and thin films an average coordination, $N_{\text {av }}>3$ yields increasingly defective interfaces. Finally, the universality of this application of constraint theory is demonstrated by showing that defect densities scale with overcoordination in the same way in thin films and at interfaces. (C) 1999 American Vacuum Society.
\end{abstract}

[S0734-211X(99)03904-9]

\section{INTRODUCTION}

As source-drain distances in field effect transistors (FETs) are scaled to $<150 \mathrm{~nm}$ and ultimately to $\sim 50 \mathrm{~nm}$, the oxide equivalent thickness, $t_{\text {ox-eq }}$ of gate dielectrics must be reduced initially to $<2 \mathrm{~nm}$, and then to $<1 \mathrm{mn}$. Values of $t_{\text {ox-eq }}$ are calculated from the experimentally determined gate capacitance in the accumulation region, $C_{\text {acc }}$, by assuming that the dielectric film or composite multilayer stack is equivalent to an $\mathrm{SiO}_{2}$ film with a static dielectric constant, $k_{0}$, of 3.8 , so that

$$
t_{\text {ox-eq }}=k_{0} \epsilon_{0} A / C_{\mathrm{acc}},
$$

where $\epsilon_{0}$ is the permittivity of free space, and $A$ is the area of the capacitor. $C_{\text {acc }}$ can be obtained directly from experimental $C-V$ data for thicker films, $t_{\text {ox-eq }}>2.5-3 \mathrm{~nm}$, at accumu-

${ }^{a}$ Electronic mail: gerry_lucovsky@ncsu.edu lation voltages $>\sim 3 \mathrm{~V}$, or from a fit to capacitance-voltage data for ultrathin dielectrics when $t_{\mathrm{ox}-\mathrm{eq}}<2.5 \mathrm{~nm}$.

At $t_{\text {ox-eq }}<1.5 \mathrm{~nm}$ direct electron tunneling through $\mathrm{SiO}_{2}$ films at $\sim 1 \mathrm{~V}$ exceeds $1 \mathrm{~A} / \mathrm{cm}^{2}$, a value at which circuit performance and reliability are degraded. One approach to reduce direct tunneling current is to replace $\mathrm{SiO}_{2}$ by physically thicker films with higher dielectric constants. The first step is this replacement process has been to substitute $\mathrm{Si}_{3} \mathrm{~N}_{4}$ for $\mathrm{SiO}_{2}$ so that the film thickness can increased by $\sim 2$, the ratio of the respective dielectric constants. Successful substitution requires (i) that the $\mathrm{Si}_{3} \mathrm{~N}_{4}$ bulk films have fixed charge and trap densities that are comparable to $\mathrm{SiO}_{2}$, i.e., $<1$ $\times 10^{11} \mathrm{~cm}^{-2}$, (ii) that the interfaces between $\mathrm{Si}$ and $\mathrm{Si}_{3} \mathrm{~N}_{4}$ have fixed charge and trap densities that are comparable to $\mathrm{Si}-\mathrm{SiO}_{2}$, i.e., $<5 \times 10^{10} \mathrm{~cm}^{-2}$, and (iii) that changes in other material and interface properties, such as tunneling masses and barriers do not offset reductions in tunneling current anticipated from increased physical thickness. Recent experi- 
mental studies have demonstrated that reductions in electron tunneling masses in $\mathrm{Si}_{3} \mathrm{~N}_{4}$ thin films, and in conduction band offset energies between $\mathrm{Si}_{3} \mathrm{~N}_{4}$ and $\mathrm{Si}$ compensate almost exactly for increases in dielectric constant that allows the use of physically thicker $\mathrm{SiO}_{2}$ films. ${ }^{1}$ These aspects of $\mathrm{Si}_{3} \mathrm{~N}_{4} / \mathrm{SiO}_{2}$ substitutions are addressed in more detail elsewhere, and suggest that composite $\mathrm{SiO}_{2} / \mathrm{Si}_{3} \mathrm{~N}_{4}$ gate dielectric films may not satisfy many of the targeted goals for aggressive scaling required in advanced the most FET devices. ${ }^{2}$

With the exception of issues relating to tunneling currents, it has been demonstrated that bulk $\mathrm{Si}_{3} \mathrm{~N}_{4}$ films prepared by remote plasma-enhanced chemical vapor deposition (RPECVD) at $300^{\circ} \mathrm{C}$, and annealed at $900{ }^{\circ} \mathrm{C}$ for at least 30 $\mathrm{s}$ in an inert, nonoxidizing ambient have bulk properties comparable to thermally grown $\mathrm{SiO}_{2}$ when incorporated into capacitors with stacked oxide/nitride/oxide (ONO) dielectrics with $\mathrm{Si}-\mathrm{SiO}_{2}$ or nitrided $\mathrm{Si}-\mathrm{SiO}_{2}$ interfaces, ${ }^{3,4}$ or in FETs with stacked oxide/nitride (ON) dielectrics with $\mathrm{Si}-\mathrm{SiO}_{2}$ or nitrided $\mathrm{Si}-\mathrm{SiO}_{2}$ interfaces. ${ }^{5-7}$ In contrast to nitrides prepared by other techniques, such as rapid thermal CVD (RTCVD), ${ }^{8}$ or jet vapor deposition (JVD), ${ }^{9}$ which generally require an oxidizing anneal after film deposition to form oxynitride alloys with low bulk defect densities, the annealed RPECVD nitrides derive their low bulk defect densities from incorporation of $\sim 10-15$ at. $\%$ hydrogen. ${ }^{4,7}$ The as-deposited RPECVD films have approximately 20-30 at. \% bonded hydrogen, mostly in near neighbor in $\mathrm{Si}-\mathrm{H}$ and SiN-H arrangements, ${ }^{10-12}$ and after the $900{ }^{\circ} \mathrm{C}$ anneal, the remaining $10-15$ at. \% is bonded in isolated $\mathrm{SiN}-\mathrm{H}$ arrangements. Detailed studies of the specific hydrogen bonding arrangements with nearest-neighbor $\mathrm{Si}-\mathrm{H}$ and/or $\mathrm{SiN}-\mathrm{H}$ groups, that readily evolve $\mathrm{H}_{2}$ molecules upon annealing, are discussed in detail elsewhere. ${ }^{11,12}$ This article focuses on issues relative to $\mathrm{Si}-\mathrm{Si}_{3} \mathrm{~N}_{4}$ interface bonding and defects.

It is shown that a direct substitution of $\mathrm{Si}_{3} \mathrm{~N}_{4}$ for $\mathrm{SiO}_{2}$ in FETs is limited by charged defects at the $\mathrm{Si}-\mathrm{Si}_{3} \mathrm{~N}_{4}$ interface that will be shown to result from constraints imposed by overcoordination in the spirit of Refs. 13-15. In particular, this article extends constraint theory, originally developed for bulk oxide and chalcogenide bulk glasses by Phillips ${ }^{13,14}$ and thin films by Lucovsky and Phillips ${ }^{15}$ and thereby provides a quantitative approach to explaining the significant differences in defect properties between $\mathrm{Si}-\mathrm{SiO}_{2}$ and $\mathrm{Si}-\mathrm{Si}_{3} \mathrm{~N}_{4}$ interfaces. Another paper at this conference by Misra and co-workers, ${ }^{7}$ presents electrical measurements on both $p$-channel (hole conducting) and $n$-channel (electron conducting) FETs, and concludes that increases in the density of donor-like defects in the lower half of the gap $p$-channel FETs render these devices totally dysfunctional. This article presents complimentary studies of $p$-channel FETs and capacitors with $\mathrm{Si}-\mathrm{Si}_{3} \mathrm{~N}_{4}$ interfaces with essentially the same result. The results reported in this paper and in Ref. 7 further demonstrate that insertion of $\sim 0.6 \mathrm{~nm}$ (or about two molecular layers) of $\mathrm{SiO}_{2}$ between the $\mathrm{Si}$ substrate and the $\mathrm{Si}_{3} \mathrm{~N}_{4}$ film deposited by RPECVD at $300^{\circ} \mathrm{C}$ and annealed in an inert ambient for at least $30 \mathrm{~s}$ at $900{ }^{\circ} \mathrm{C}$ restores interface devices properties to essentially the same

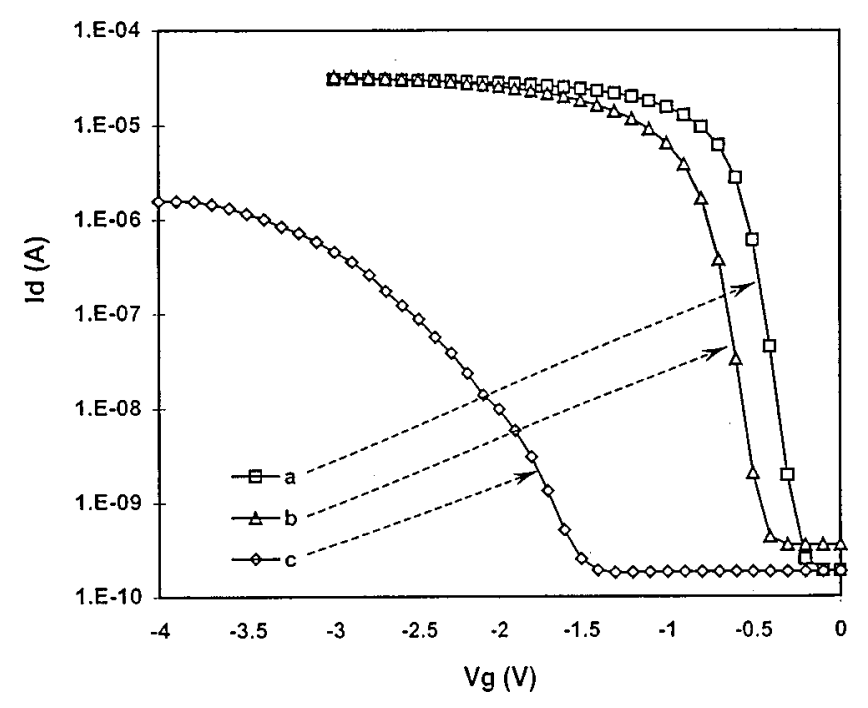

FIG. 1. Drive current-gate voltage $\left(I_{d}-V_{g}\right)$ characteristics for PMOSFETs with $t_{\text {ox-eq }} \sim 2 \mathrm{~nm}$ : (a) a $1.5 \mathrm{~nm}$ oxide separating a $1.0 \mathrm{~nm}$ nitride from the $\mathrm{Si}$ substrate, (b) a $0.6 \mathrm{~nm}$ oxide separating a $2.4 \mathrm{~nm}$ nitride from the Si substrate, and (c) a $4 \mathrm{~nm}$ nitride layer. The threshold voltage shift between (a) and $(b)$ is due in part to substrate doping differences $(0.16 \mathrm{~V})$ and in part to positive charge at the oxide-nitride interface $(0.04 \mathrm{eV})$.

level as in devices with thermally grown $\mathrm{Si}-\mathrm{SiO}_{2}$ interfaces. This dramatic change in interfacial defect properties will also be explained in the context of the extension of constraint theory.

Section II presents experimental results for $\mathrm{Si}_{-} \mathrm{Si}_{3} \mathrm{~N}_{4}$ interfaces and Sec. III discusses constraint theory as proposed originally for bulk glasses ${ }^{13,14}$ and thin films. ${ }^{15}$ The application of constraint theory to thin films is used to develop quantitative relationships between departures from ideal average bonding coordination and defect concentrations, which serve as a basis for the development of a quantitative approach to defects semiconductor-dielectric interfaces and internal dielectric interfaces. Section IV extends constraint theory to interfaces and Sec. V applies this extended theory to the experimental results of Sec. II. The model is further generalized in Sec. V to interfaces between $\mathrm{Si}$ and the socalled alternative high-K dielectrics such as $\mathrm{TiO}_{2}$ (Ref. 16) and $\mathrm{Ta}_{2} \mathrm{O}_{5}$ (Ref. 17) that are being considered as replacements for $\mathrm{SiO}_{2}$ in aggressively scaled FET devices. In Sec. $\mathrm{V}$, the theory is applied to internal interfaces in stacked dielectrics, such as the oxide/nitride interfaces of Refs. 1-6. Finally, in Sec. VI, the universality of quantitative defect scaling with overcoordination in thin films and at interfaces is demonstrated.

\section{EXPERIMENTAL RESULTS FOR Si-Si ${ }_{3} \mathrm{~N}_{4}$ INTERFACES}

Figure 1 displays current-voltage, $I-V$, curves for $p$-channel FETs for different gate dielectrics with $t_{\text {ox-eq }}$ $\sim 2 \mathrm{~nm}$ : (i) a $4 \mathrm{~nm}$ RPECVD nitride, (ii) a $0.6 \mathrm{~nm}$ plasmaoxide with a $2.4 \mathrm{~nm}$ RPECVD nitride, and (iii) a $1.5 \mathrm{~nm}$ thermal oxide with a $1.0 \mathrm{~nm}$ RPECVD nitride. The substrates are $\mathrm{Si}(100)$, doped to $5 \times 10^{17} \mathrm{~cm}^{-3}$ for (i) and (iii) 1.1 


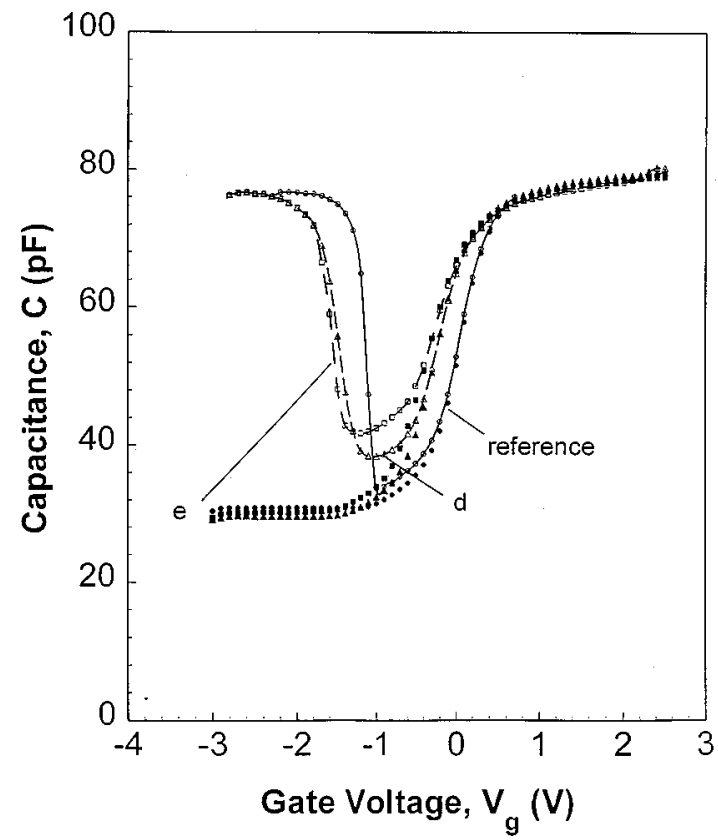

FIG. 2. $C-V$ characteristics demonstrate shift in flatband voltage due to positive charge, and increased separation between high frequency and quasistatic plots due to interface trapping accompanying direct deposition of thin nitride films onto $\mathrm{Si}$. Each of these capacitors has $t_{\text {ox-eq }} \sim 2 \mathrm{~nm}$ : (i) a reference oxide and (ii) two stacked $\mathrm{NO}$ structures with the nitride layer in contact with the Si substrate. The nitride layer thickness is $0.4 \mathrm{~nm}$ for (d), and $0.8 \mathrm{mn}$ for (e)

$\times 10^{18} \mathrm{~cm}^{-3}$ for (ii). $I-V$ traces for (i) and (iii) display excellent turn-on behavior and the same current drive, with differences in threshold voltage between (ii) and (iii) derived primarily from differences in substrate doping noted above $(\sim 0.160 \mathrm{~V}$ out of the $0.200 \mathrm{~V}$ difference). In contrast, for the FET with the $4 \mathrm{~nm}$ nitride: (i) threshold voltage is shifted to negative voltages by $>1 \mathrm{~V}$, (ii) turn-on is soft, and (iii) channel drive current is reduced by $\sim 50$. Figure 2 displays capacitance-voltage, $C-V$, characteristics for $p$-type metaloxide semiconductor (PMOS) devices with $t_{\text {ox-eq }} \sim 4.3 \mathrm{~nm}$ : one with a plasma-oxide, and two with stacked dielectrics with RPECVD nitride interface layers of 0.4 and $0.8 \mathrm{~nm}$, respectively. Shifts in threshold (and flatband) voltage relative to $\mathrm{Si}-\mathrm{SiO}_{2}$ indicate increased fixed charge for devices with nitride interfaces: $\Delta q_{f}=C_{\mathrm{ox}} \Delta V_{\mathrm{th}}$ (or $\Delta V_{\mathrm{fb}}$ ). Qualitatively similar results have been obtained for $n$-type metaloxide-semiconductor (NMOS) devices with nitride layer interfaces. ${ }^{7}$ Figure 3 displays current density-voltage, $J-V$, plots for a capacitor fabricated on lightly doped $n$-type substrates and $n^{+}$polycrystalline $\mathrm{Si}$ gate electrodes for an oxide thickness of $2.5 \mathrm{~nm}$ as determined from analysis of $C-V$ data. ${ }^{18}$ There are two types of devices shown in Fig. 3: (i) the device exhibiting the higher current was prepared by remote plasma processes that resulted in a non-nitrided interface, whereas (ii) the device exhibiting reduced tunneling current was prepared by remote plasma process that resulted in a monolayer nitrided interface. ${ }^{18}$ The $C-V$ data establish that the flatband voltages are determined by the substrate and polycrystalline Si doping and not changed by interface nitri-

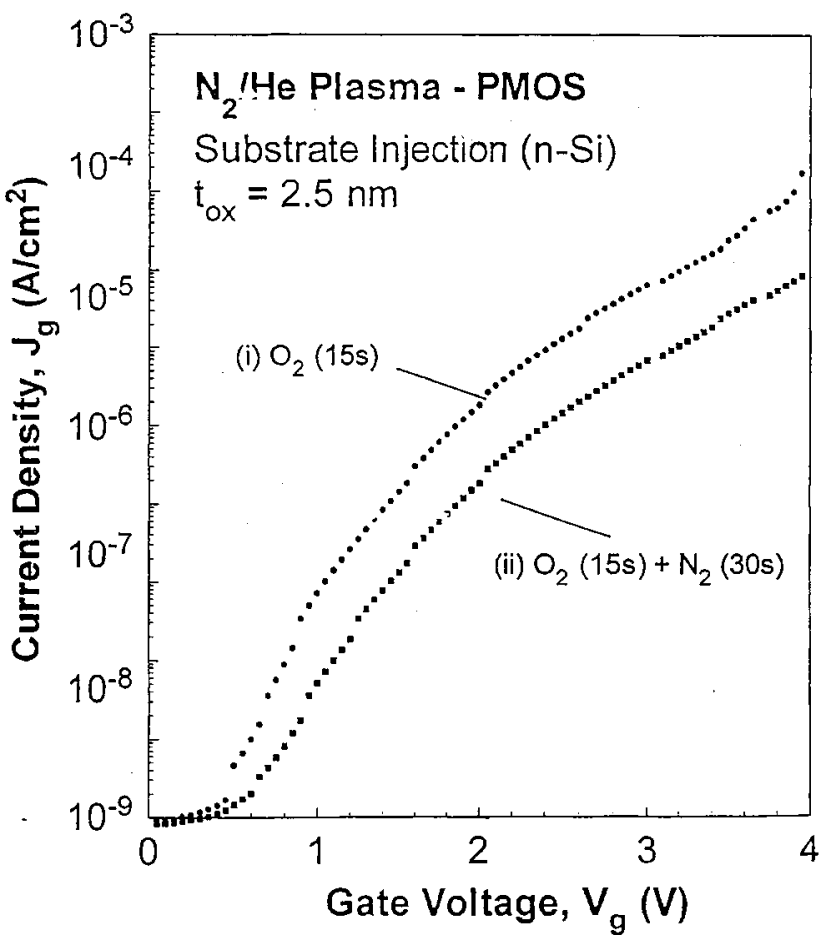

FIG. 3. $J-V$ characteristics for capacitors prepared on lightly doped $n$-type $\mathrm{Si}(100)$ with $n^{+}$polycrystalline $\mathrm{Si}$ gate electrodes for $t_{\text {ox-eq }} \sim 2.5 \mathrm{~nm}$. The upper curve is for a device with an $\mathrm{RPECVD} \mathrm{SiO}_{2}$ layer and a non-nitrided $\mathrm{Si}-\mathrm{SiO}_{2}$ interface, and the lower curve is for a device with an RPECVD $\mathrm{SiO}_{2}$ layer and a monolayer nitrided $\mathrm{Si}-\mathrm{SiO}_{2}$ interface.

dation. For this pair of devices with the same effective thickness, the tunneling current is reduced by the monolayer interface nitridation, indicating that insertion of a monolayer of nitride at the $\mathrm{Si}-\mathrm{SiO}_{2}$ interface is beneficial. This means that monolayer interface nitridation is qualitatively different from having one or more molecular layers of nitride present the interface with the crystalline $\mathrm{Si}$ substrate.

Summarizing the data in Figs. 1-3 and data presented in other papers, ${ }^{19,20}$ the $I-V$ and $C-V$ data establish that: (i) that deposition of $\mathrm{Si}_{3} \mathrm{~N}_{4}$ films by RPECVD at Si-dielectric interfaces degrades interface properties, (ii) that interface properties can be effectively restored by interposing an ultrathin $(\sim 0.6 \mathrm{~nm})$ layer of plasma-grown $\mathrm{SiO}_{2}$ between the $\mathrm{Si}$ substrate and the RPECVD $\mathrm{Si}_{3} \mathrm{~N}_{4}$ film, and finally, (iii) monolayer interface nitridation either during remote plasma oxidation, ${ }^{19}$ or after remote plasma oxidation ${ }^{18}$ resulted in improvements in interface properties, rather than degradation. ${ }^{7,20}$

\section{CONSTRAINT THEORY FOR BULK GLASSES AND THIN FILMS}

Phillips showed that fully bonded, strain-free threedimensional continuous random networks (CRNs) can be formed at compound and alloy chemical compositions by counting average bond constraints associated with applicable valence force fields, $C_{\mathrm{av}}$, and then matching constraints to the dimensionality of the network structure. ${ }^{13-15}$ For threedimensional melt-quenched glasses these fields are simply 
bond-stretching and bond-bending valence forces. The quantitative relationships between (i) local bonding coordination and geometry, and (ii) constraints are presented in the next paragraph. Under the condition of exactly matching constraints to network dimensionality, the average coordination number/atom, $N_{\mathrm{av}}$, is 2.4 , corresponding to the well-known glass-formers arsenic trisulfide and arsenic triselenide, $\mathrm{As}_{2} \mathrm{~S}_{3}$ and $\mathrm{As}_{2} \mathrm{Se}_{3}$, respectively. Good glass formation has also been obtained in the $\mathrm{Ge}-\mathrm{S}$ and $\mathrm{Ge}-\mathrm{Se}$ systems, even at the compound compositions $\left(\mathrm{GeS}_{2}\right.$ and $\left.\mathrm{GeSe}_{2}\right)$, where $N_{\mathrm{av}}$ $=2.67$, and $C_{\mathrm{av}}=3.67$, exceeding the optimum value of 3 . Recent studies have shown ideal-glass formation in $\mathrm{Ge}-\mathrm{S}$ and $\mathrm{Ge}-\mathrm{Se}$ alloy systems occurs at a chalcogenide-rich composition corresponding to $N_{\mathrm{av}} \sim 2.45$ with a value of $C_{\mathrm{av}}$ close to $3 .^{21}$ For the $\mathrm{SiO}_{x}(x \leqslant 2)$ system, O-atom bondbending forces are ineffective at fictive (or quench) temperatures above the effective viscoelastic relaxation temperature of $\sim 1000^{\circ} \mathrm{C}$, so that the applicable forces in bulk-quenched glasses are bond-stretching forces on both atoms, and bond bending forces only on the Si atoms. $N_{\mathrm{av}}=2.67$ at the composition of $\mathrm{SiO}_{2}$, and the number of constraints per atom, neglecting the O-atom bond-bending forces, is also $C_{\mathrm{av}}=3$. This explains the ease of glass formation by quenching from melts exceeding the viscoelastic relaxation temperature. ${ }^{13-15}$

As indicated above, the calculation of $C_{\mathrm{av}}$ is based on counting constraints associated with valence forces. The number of bond-stretching constraints/atom is $m / 2$, where $m$ is the coordination number, and for three-dimensionally coordinated atoms, the number of bond-bending constraints is $2 m-3 .{ }^{13}$ Applied to $\mathrm{As}_{2} \mathrm{~S}_{3}$, the number of bond-stretching constraints is equals 6 , and the number of bond-bending constraints is equals 9 , so that the total number of constraints is 15, and $C_{\text {av }}=3$. Applied to $\mathrm{SiO}_{2}$ glasses that are quenched from temperatures exceeding the viscoelastic relaxation temperature, the total number of bond-stretching constraints is 4 , and the number of bond-bending constraints is associated with $\mathrm{Si}$ atoms is 5 , so that $C_{\mathrm{av}}=3$, as well.

The bonding of $\mathrm{N}$ in $\mathrm{Si}-\mathrm{N}$ and $\mathrm{Ge}-\mathrm{N}$ systems is planar or effectively two dimensional with the $\mathrm{N}$ atom bonded to three $\mathrm{Si}$ or Ge atoms in an $\mathrm{NX}_{3}$ geometry, $X=\mathrm{Si}$ or Ge. ${ }^{22}$ This bonding arrangement is stabilized by $p \pi-d \pi$ interactions in which the nonbonding pair of the $\mathrm{N}$ atom in $p_{z}$ orbital perpendicular the $\mathrm{Si}(\mathrm{Ge}-\mathrm{N})$ bonding $x-y$ plane backdonates to unoccupied antibonding $\mathrm{Si}$ or Ge orbitals that have a $d^{3} p$ symmetry. As a consequence of this planar bonding of $\mathrm{N}$ atoms in $\mathrm{Si}-\mathrm{N}$ alloys, the number of $\mathrm{N}$-atom bond-bending constraints is reduced to $m-1$, so that for $\mathrm{Si}_{3} \mathrm{~N}_{4}, C_{\text {av }}=5.0$, and $N_{\mathrm{av}}=3.43$. However, this value of $C_{\mathrm{av}}$ is significantly higher than the network dimensionality so that glass formation from the melt does not occur.

The optimum value of $C_{\mathrm{av}}=3$ applies to ideal meltquenched networks, and this criterion must be modified for vapor-deposited films prepared at temperatures well below the glass transition temperature. These films are generally not strain free, and contain voids as well. ${ }^{14}$ For nonhydrogenated $a$-Si $N_{\text {av }}=4$ and $C_{\text {av }}=7$, and hydrogen-free $a$-Si films produced by sputtering generally contain high concentrations
TABLE I. Calculated values of $N_{\mathrm{av}}$ and $N_{\mathrm{av}}$ for melt-quenched and deposited dielectrics.

\begin{tabular}{|c|c|c|c|c|}
\hline \multirow{2}{*}{$\frac{\text { Material }}{\mathrm{As}_{2} \mathrm{~S}(\mathrm{Se})_{3}}$} & \multicolumn{2}{|c|}{$\begin{array}{l}\text { Atomic coordination } \\
\text { and (dimensionality) } \\
\text { bulk-quenched glasses }\end{array}$} & \multirow{2}{*}{$\begin{array}{l}N_{\text {av }} \\
2.40\end{array}$} & \multirow{2}{*}{$\begin{array}{l}C_{\mathrm{av}} \\
3.00\end{array}$} \\
\hline & As: 3(3) & $\mathrm{S}(\mathrm{Se}): 2(3)$ & & \\
\hline $\mathrm{GeS}(\mathrm{Se})_{2}$ & Ge: 4(3) & $\mathrm{S}(\mathrm{Se}): 2(3)$ & 2.67 & 3.67 \\
\hline $\mathrm{GeS}(\mathrm{Se})_{3.5}$ & Ge: 4(3) & $\mathrm{S}(\mathrm{Se}): 2(3)$ & 2.44 & 3.10 \\
\hline \multirow[t]{2}{*}{$\mathrm{SiO}_{2}$} & $\mathrm{Si}: 4(2) \mathrm{O}: 2$ & & 2.67 & 3.00 \\
\hline & \multicolumn{2}{|c|}{ Plasma-deposited films } & & \\
\hline $\mathrm{SiO}_{2}$ & \multicolumn{2}{|c|}{ Si: 4(3)O: 2(3) } & 2.67 & 3.67 \\
\hline $\mathrm{Si}_{3} \mathrm{~N}_{4}$ & \multicolumn{2}{|c|}{ Si: 4(3)N: 3(2) } & 3.43 & 5.00 \\
\hline$a-\mathrm{Si}: \mathrm{N}: \mathrm{H}^{\mathrm{b}}$ & \multicolumn{2}{|c|}{ Si: 4(3), N: 3(2), H: 1(1) } & 2.68 & 3.58 \\
\hline$a-\mathrm{Si}$ & \multicolumn{2}{|c|}{ Si: $4(3)$} & 4.00 & 7.00 \\
\hline$a-\mathrm{Si}: \mathrm{H}^{\mathrm{c}}$ & \multicolumn{2}{|c|}{ Si: 4(3)H: 1(1) } & 3.50 & 5.70 \\
\hline
\end{tabular}

${ }^{\mathrm{a} N e g l e c t s ~ b o n d-b e n d i n g ~ c o n s t r a i n t s ~ f o r ~} \mathrm{O}$ atoms.

${ }^{\mathrm{b}}[\mathrm{N}]=0.42,[\mathrm{Si}]=0.28$, and $[\mathrm{H}]=0.30$.

$\mathrm{c}[\mathrm{Si}]=0.8,[\mathrm{H}]=0.2$.

of dangling bonds, e.g., the concentration of Si dangling bonds detected by electron spin resonance is $\sim 10^{18} \mathrm{~cm}^{-3}$ after optimized thermal annealing. ${ }^{23}$ The hydrogenated films also have internal voids which serve to reduce strain, thereby reducing the effective number of dangling bond defects below a value that is simply determined by $C_{\mathrm{av}} \cdot{ }^{15} N_{\mathrm{av}}$ and $C_{\mathrm{av}}$ can be reduced further by hydrogenation leading to significant reductions in the dangling bond density. For example, for an $a-\mathrm{Si}: \mathrm{H}$ alloy with $10-15$ at. $\% \mathrm{H}, N_{\mathrm{av}}=3.5$, and $C_{\mathrm{av}}$ $=5.7$. These alloys display $\mathrm{Si}$ atom dangling bond densities of order $5 \times 10^{16} \mathrm{~cm}^{-3}$, which is low enough for promoting good semiconductor properties as for example high substitutional doping efficiencies, thereby allowing the use of these doped $a$-Si:H films in photovolatic cells and thin film transistors (TFTs). ${ }^{24}$

Table I includes calculated values of $N_{\mathrm{av}}$ and $C_{\mathrm{av}}$ for ideal melt-quenched glasses, and for thin films. As shown in Fig. 4, increases in $C_{\text {av }}$ correlate linearly with increases in $N_{\text {av }}$ so that either descriptive can be applied to bulk-quenched glasses or plasma-deposited amorphous materials and as shall be demonstrated in the next section, to crystalline Sidielectric interfaces and internal dielectric interfaces as well. In the remainder of this article, the $N_{\text {av }}$ metric will be used in discussing scaling of defects.

As discussed above, if both bond-bending and stretching forces are present, the optimal average coordination number, $N_{\mathrm{av}}^{*}$, which matches constraints to degrees of freedom is 2.4 as in $\mathrm{As}_{2} \mathrm{~S}(\mathrm{Se})_{3}$, however, for $\mathrm{SiO}_{2}$ bulk glasses, $N_{\mathrm{av}}^{*}=2.67$ is optimal because bond-bending forces at $\mathrm{O}$ atoms are too weak to function as significant constraints at growth or annealing temperatures. ${ }^{15}$ For overconstrained networks such as in thin film $\mathrm{Si}_{3} \mathrm{~N}_{4}\left(N_{\mathrm{av}}=3.43\right)$, Si-atom stretching constraints are stronger than bending constraints, so that strain energy accumulates along the bending constraints. The average $\mathrm{Si}-\mathrm{N}-\mathrm{Si}$ bond angle $\theta_{i j}$ is distorted from the ideal local value $\theta_{i j}^{*}$ by an amount

$$
\delta \theta \propto \delta N_{\mathrm{av}}^{*}=N_{\mathrm{av}}-N_{\mathrm{av}}^{*} .
$$




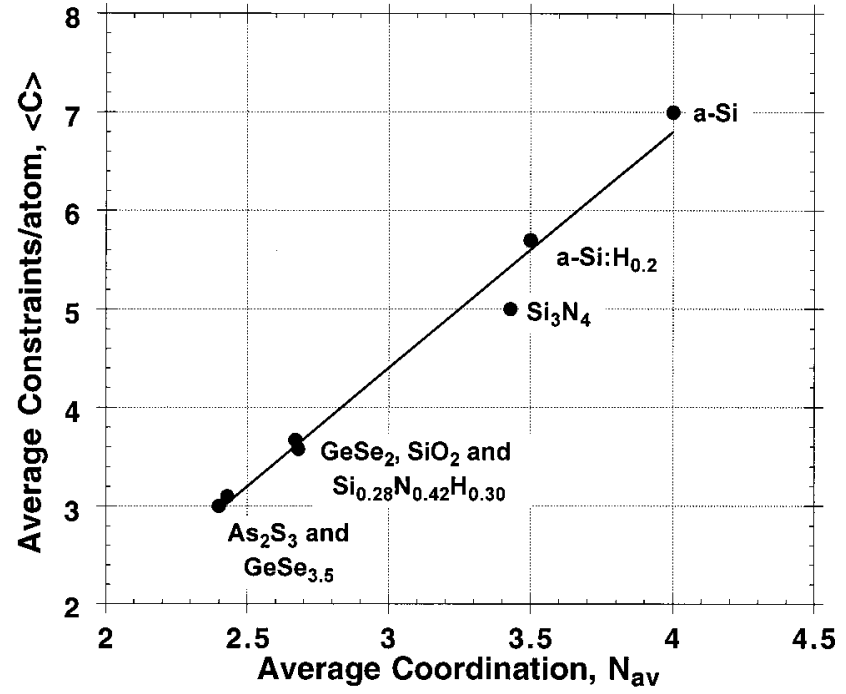

FIG. 4. Bonding constraints per atom, $C_{\mathrm{av}}$ vs average number of bonds per atom, $N_{\mathrm{av}}$, for bulk-quenched glasses and deposited thin films (see Table I). The line in this figure is a least-squares fit the data points, excluding the value for bulk-quenched $\mathrm{SiO}_{2}$.

Since total strain energy is proportional to $(\delta \theta)^{2},{ }^{25}$ it is then expected that defect creation, e.g., dangling $\mathrm{Si}$ or $\mathrm{N}$ bonds, will be proportional to $\left\{N_{\mathrm{av}}-N_{\mathrm{av}}^{*}\right\}^{2}$. Similar considerations apply to other thin film materials as well. Experiments have shown that $N_{\text {av }} \sim 3$ represents a reasonable demarcation criterion between low defect density $\left(\sim 10^{16} \mathrm{~cm}^{-3}\right)$, and increasingly defective materials. ${ }^{15}$ Equation (2) is also consistent with the structure of noncrystalline solids in which the statistical distribution of bond angles is much larger than the statistical spread in bond lengths, $\delta r$.

\section{EXTENSION OF CONSTRAINT THEORY TO Si- DIELECTRIC INTERFACES}

Before applying constraint theory to Si-dielectric interfaces, it is important understand other factors than can play a role in interface bonding and the associated electronic structure. There are at least four factors related to bonding that can promote formation of interfacial defects; these are (i) differences between electronic charge required for bonding and for balancing the nuclear charge of the constituent atoms as first identified by Harrison and co-workers for group IVgroup III-V heterojunctions such as $\mathrm{Ge}-\mathrm{GaAs}$ (heterovalent as opposed to isovalent bonding), ${ }^{26}$ (ii) interfacial dipoles produced by charge transfer between the Si substrate and the gate dielectric material, ${ }^{27,28}$ (iii) molar volume differences between the Si substrate and gate dielectric that produce interfacial strain, and generally require interfacial dangling bond formation, and finally, (iv) overconstrained bonding due to differences between the average number of bonds per atom on each side of the interface. ${ }^{29}$ Going down this list in order; (i) is not a consideration since both $\mathrm{SiO}_{2}$ and $\mathrm{Si}_{3} \mathrm{~N}_{4}$ can bond to a $\mathrm{Si}$ substrate by forming isovalent bonds between substrate $\mathrm{Si}$ atoms and either $\mathrm{O}$ or $\mathrm{N}$ atoms of the respective dielectrics. Second, it has been shown that inter-

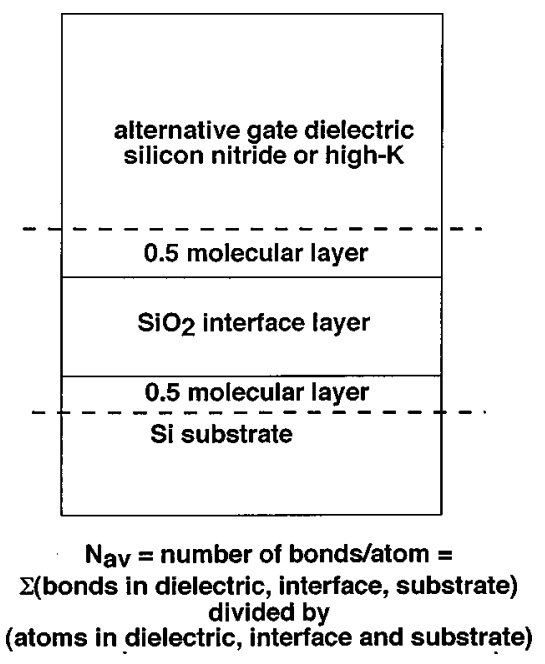

FIG. 5. Schematic representation of interface constituents used in the calculation of $N_{\text {av }}$ for Si-dielectric interfaces.

facial charge transfer dipoles in (ii) result in relatively small differences in band offset energies at the $\mathrm{Si}-\mathrm{SiO}_{2}$ and $\mathrm{Si}-\mathrm{Si}_{3} \mathrm{~N}_{4}$ interfaces, and that charge transfer is smaller at the nitride interfaces that at oxide interfaces. Therefore it is not likely that these dipoles play a determinant role in defect or defect precursor formation since the defect densities at the $\mathrm{Si}-\mathrm{Si}_{3} \mathrm{~N}_{4}$ interfaces are larger than those at the $\mathrm{Si}-\mathrm{SiO}_{2}$ interfaces. Interfacial strain as in (iii) has been shown to be an important factor in interface quality. It has been shown that for thermally grown oxides on $\mathrm{Si}$ in a thickness range that extends to at least $100 \mathrm{~nm}$, the residual density of interface traps, $D_{\text {it }}$, scales linearly with integrated strain in the oxide layer. ${ }^{30}$ Since the molar volume mismatch between $\mathrm{Si}_{3} \mathrm{~N}_{4}$ and $\mathrm{Si}$ is reduced with respect to that of $\mathrm{SiO}_{2}$ to $\mathrm{Si}$, residual interface strain cannot be the driver for the increased defect concentrations at $\mathrm{Si}-\mathrm{Si}_{3} \mathrm{~N}_{4}$ interfaces. The remainder of this section focus on the final interface consideration in (iv) dealing with bonding constraints.

The abruptness of $\mathrm{Si}-\mathrm{SiO}_{2}$ interfaces suggests that the defect density of thermally grown oxides and optimally annealed deposited oxides is a characteristic function of their bonding chemistry and structure. Experience with good glass-formers such as $\mathrm{SiO}_{2}$ and $\mathrm{As}_{2} \mathrm{Se}_{3}$ has shown that as long as only single bonds are present charge transfer plays a minor part in determining structure. The major factor is the network stress which arises for a given space-filling bonding topology, and this factor is expected to extend to interfaces as well.

Extension of constraint theory to Si-dielectric-interfaces considers three interfacial contributions to $N_{\mathrm{av}}$ : (i) the $\mathrm{Si}$ substrate represented by one-half a $\mathrm{Si}$ atom, (ii) an ultrathin oxide or nitride interfacial layer $(0.3-0.6 \mathrm{~nm})$, and (iii) the bulk dielectric by one-half a molecular layer (see Fig. 5). Table II includes calculations of $N_{\text {av }}$ for representative Sidielectric interfaces. When a demarcation level $N_{\text {av }} \sim 3$ is applied between device-quality and highly defective interfaces, these calculations are in excellent agreement with experiment (see Figs. 1 and 2). For example, the model con- 
TABLE II. Average bonding coordination at Si-dielectric interfaces.

\begin{tabular}{lll}
\hline \hline \multicolumn{1}{c}{ Material system } & Average coordination $\left(N_{\text {av }}\right)$ & Electrical quality \\
\hline $\mathrm{Si}-\mathrm{SiO}_{2}(1.5$ molecular layers $)$ & 2.8 & excellent \\
$\mathrm{Si}-\mathrm{Si}_{3} \mathrm{~N}_{4}(1.5$ molecular layers $)$ & 3.5 & very poor (Fig. 1) \\
$\mathrm{Si}-\left\{\mathrm{SiO}_{2}\right\}(t)-\mathrm{Si}_{3} \mathrm{~N}_{4}$ & $t=0.5 \mathrm{~nm}: 3.1$ & excellent (Fig. 1) \\
$t=$ oxide layer thickness & $t=1.5 \mathrm{~nm}: 2.9$ & excellent (Fig. 1) \\
$\mathrm{Si}-\left\{\mathrm{Si}_{3} \mathrm{~N}_{4}\right\}(t)-\mathrm{SiO}_{2}$ & $t=0.4 \mathrm{nm:} 3.3$ & poor (Fig. 2) \\
$t=$ oxide layer thickness & $t=0.8 \mathrm{nm:} 3.4$ & poor (Fig. 2) \\
$\mathrm{Si}-\mathrm{N}_{-}-\mathrm{SiO}_{2}\{1$ monolayer $\}$ & 2.8 & excellent (Ref. 18) \\
$\mathrm{Si}-\left(\mathrm{SiO}_{2}\right)_{0.9}\left\{\mathrm{Si}_{3} \mathrm{~N}_{4}\right)_{0.1}$ & 10 at. $\% \mathrm{~N}: 2.9$ & very good (Ref. 31) \\
$\mathrm{Si}-\left(\mathrm{SiO}_{2}\right)_{0.7}\left(\mathrm{Si}_{3} \mathrm{~N}_{4}\right)_{0.3}$ & 26 at. $\% \mathrm{~N}: 3.1$ & poor (Ref. 31) \\
$\left.\mathrm{Si}-\mathrm{TiO}_{2}\right\}^{\mathrm{a}}(1.5$ molecular layers $)$ & 4.0 & unreported \\
$\left.\mathrm{Si}-\mathrm{Ta}_{2} \mathrm{O}_{5}\right\}^{\mathrm{b}}(1.5$ molecular layers $)$ & 3.5 & unreported \\
$\left.\mathrm{Si}-\mathrm{Al}_{2} \mathrm{O}_{3}\right\}^{\mathrm{c}}(1.5$ molecular layers $)$ & 3.6 & unreported \\
\hline \hline
\end{tabular}

${ }^{a}$ Average coordination: $[\mathrm{Ti}]=6,[\mathrm{O}]=3.0$ (rutile/anatase bonding).

${ }^{\mathrm{b}}$ Average coordination: $[\mathrm{Ta}]=6,[\mathrm{O}]=2.4$ (Ref. 32).

${ }^{\mathrm{c}}$ Average coordination: $\mathrm{Al}=[4.5],[\mathrm{O}]=3.0$ (3:1 ratio of tetrahedral to octahedral sites, see Ref. 33).

firms that $\mathrm{Si}-\mathrm{SiO}_{2}$ interfaces are expected to display excellent interface properties $\left(N_{\mathrm{av}} \sim 2.8\right)$, whereas $\mathrm{Si}-\mathrm{Si}_{3} \mathrm{~N}_{4}$ interfaces are not $\left(N_{\mathrm{av}} \sim 3.5\right)$. Equally important, the calculations demonstrate that interposition of ultrathin $\mathrm{SiO}_{2}$ layers between $\mathrm{Si}$ and $\mathrm{Si}_{3} \mathrm{~N}_{4}$ results in values of $N_{\text {av }} \sim 3$ consistent with very good electrical properties as in Fig. 1, whereas interposition of ultra thin $\mathrm{Si}_{3} \mathrm{~N}_{4}$ layers between $\mathrm{Si}$ and $\mathrm{SiO}_{2}$ results in $N_{\mathrm{av}}>3$ and degraded electrical performance as in Fig. 2 Figure 6 is based on the data of Figs. 1 and 2, and demonstrates that defect scaling for bulk films, Eq. (1), also holds at interfaces. The defect densities, in this case increases fixed positive charge, $\Delta q_{f}$,

$$
\Delta q_{f}=C_{\mathrm{ox}} \Delta V_{\mathrm{th}}\left(\text { or } \Delta V_{\mathrm{fb}}\right),
$$

scale with shifts of the flatband or threshold voltages $\left(\Delta V_{\mathrm{fb}}\right.$ or $\left.\Delta V_{\mathrm{th}}\right)$, from values anticipated from considerations of the substrate doping and gate electrode material; is the oxide capacitance, $C_{\mathrm{ox}} \sim C_{\mathrm{acc}}$.

The model can also been applied to interfaces between $\mathrm{Si}$ and (i) silicon oxynitride alloys and (ii) alternative high- $K$

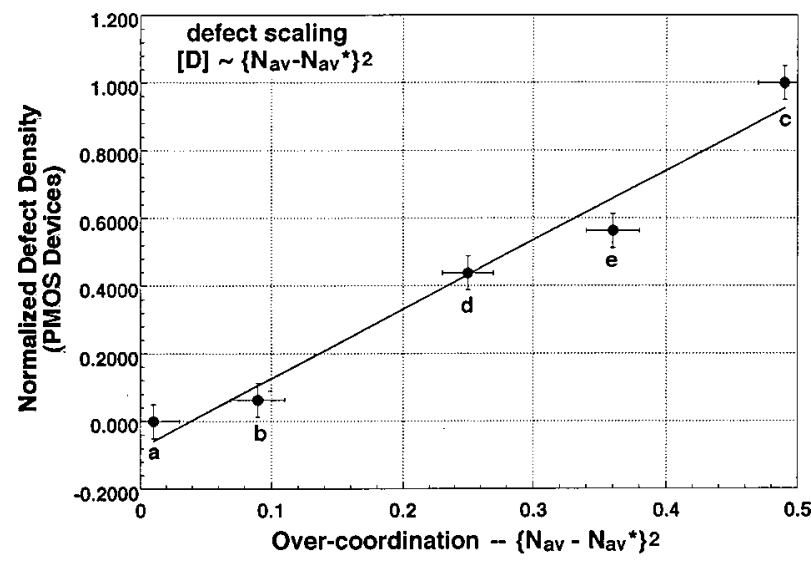

FIG. 6. Plot of normalized defect density as a function of $\left\{N_{\mathrm{av}}-N_{\mathrm{av}}^{*}\right\}^{2}$, where $N_{\mathrm{av}}^{*}$ is the value for an ideal $\mathrm{Si}-\mathrm{SiO}_{2}$ interface. Data points $\mathrm{a}, \mathrm{b}$, and $\mathrm{c}$ are from Fig. 1, and d and e from Fig. 2, and the solid line is a linear regression analysis of the data points. dielectrics. For oxynitride alloys a maximum interfacial $\mathrm{N}$ incorporation for low defects of $\sim 15$ at. $\%$ as indicated by the value of $N_{\text {av }}$ in Table II; is consistent with results of Vogel et al. ${ }^{31}$ The model calculations for $\mathrm{Ta}_{2} \mathrm{O}_{5}, \mathrm{TiO}_{2}$, and $\mathrm{Al}_{2} \mathrm{O}_{3}$ explain the necessity for ultrathin $\mathrm{SiO}_{2}$ layers between the Si substrate and these high- $K$ oxides (see, for example, Ref. 17). The model thereby establishes important limitations for extension for gate dielectric interfaces other than $\mathrm{Si}-\mathrm{SiO}_{2}$. Specifically: (i) $\mathrm{Si}_{3} \mathrm{~N}_{4}$ cannot be substituted for $\mathrm{SiO}_{2}$ at $\mathrm{Si}$ substrates; and (ii) substitution of more highly coordinated high- $K$ dielectrics such as $\mathrm{Ta}_{2} \mathrm{O}_{5}$, etc., requires $\mathrm{SiO}_{2}$, or monolayer nitrided $\mathrm{SiO}_{2}$ interfaces, thus establishing a limitation on the extent to which $t_{\text {ox-eq }}$ can be reduced below $1 \mathrm{~nm}$.

\section{EXTENSION OF CONSTRAINT THEORY TO INTERNAL DIELECTRIC INTERFACES}

As noted above, the integration of high- $K$ alternative gate dielectrics into aggressively scaled devices for ultrahigh density integrated circuits will require compliant interface layers to bridge reduce bond constraint interfacial defects. It is

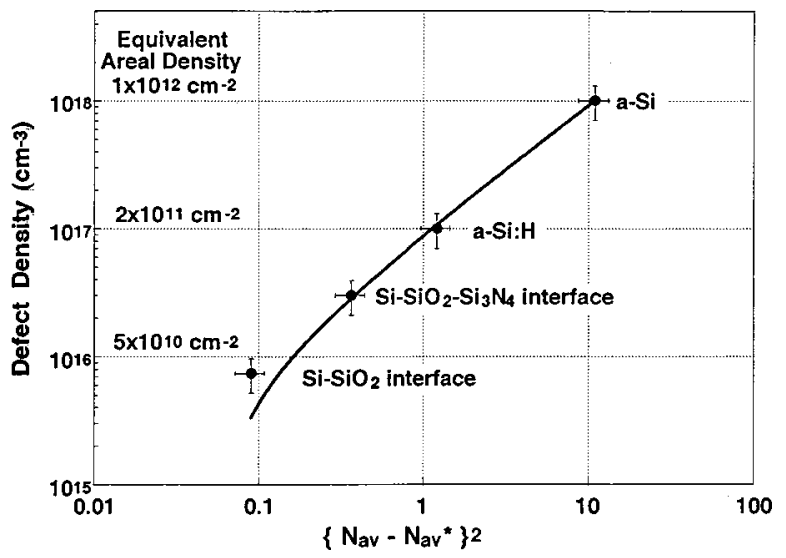

FIG. 7. Log-log plot of volume defect density vs $\left\{N_{\mathrm{av}}-N_{\mathrm{av}}^{*}\right\}^{2}$, where $N_{\mathrm{av}}^{*}$ $=2.4$ for ideal three-dimensional network structures. The solid line is a linear regression analysis of the data points. 
therefore necessary to consider bond-constraint induced defects at the internal dielectric layer and the high- $K$ materials. This has been studied in ONO stacks, where the density of positively charged defects at ON interfaces, well separated from the $\mathrm{Si}-\mathrm{SiO}_{2}$ interface $(\sim 5 \mathrm{~nm})$, was found to be $\sim 3$ $\times 10^{11} \mathrm{~cm}^{-2}$ for stacked dielectrics deposited by RPECVD at $300{ }^{\circ} \mathrm{C}$, and annealed in inert ambients at $900{ }^{\circ} \mathrm{C}$. ${ }^{2}$ Similar defect densities have been reported ${ }^{20}$ for internal $\mathrm{ON}$ interfaces even when the $\mathrm{SiO}_{2}$ layer thickness is reduced to $<1$ nm.

A two component model similar to the one developed earlier in this article for the Si-dielectric interface structure has been used as a basis for this calculation. In this model, $N_{\text {av }}$ is simply the average of the $N_{\text {av }}$ values of the interface constituents, so for $\mathrm{SiO}_{2}-\mathrm{Si}_{3} \mathrm{~N}_{4}$ internal interfaces, $N_{\text {av }} \sim 3$, consistent with the interfacial defect concentrations in the low $10^{11} \mathrm{~cm}^{-2}$ regime. Since $N_{\mathrm{av}}$ values are also $\sim 3.5$ for other candidate high- $K$ materials such as $\mathrm{Al}_{2} \mathrm{O}_{3}$ and $\mathrm{Ta}_{2} \mathrm{O}_{5}$, similar interfacial defect densities are anticipated. This in agreement with experimental results reported for stacked $\mathrm{SiO}_{2}-\mathrm{Ta}_{2} \mathrm{O}_{5}$ dielectrics. ${ }^{17}$ The effect of these interfacial defects on performance and reliability has yet to be fully evaluated, but it is expected to a factor due to the large change in the longitudinal electric field at internal dielectric interfaces between $\mathrm{SiO}_{2}$ and alternative high- $K$ dielectric materials. The electric field in the $\mathrm{SiO}_{2}$ will be the same as that calculated for a homogeneous oxide with a thickness equal to $t_{\text {ox-eq }}$, whereas the field in the high- $K$ dielectric is reduced by the dielectric constant ratio.

\section{SUMMARY}

It has been shown how constraint theory originally developed for bulk glasses ${ }^{13,14}$ and thin films, ${ }^{15}$ can be extended to (i) interfaces between crystalline $\mathrm{Si}$ and noncrystalline gate dielectric materials such as $\mathrm{SiO}_{2}, \mathrm{Si}_{3} \mathrm{~N}_{4}$, etc., and (ii) internal interfaces in stacked gate dielectrics such as $\mathrm{SiO}_{2}-\mathrm{Si}_{3} \mathrm{~N}_{4}$, $\mathrm{SiO}_{2}-\mathrm{Ta}_{2} \mathrm{O}_{5}$. For the thin film materials, and the two interfacial materials systems, $N_{\mathrm{av}} \sim 3$ represents a demarcation between device-quality and increasingly defective materials and interfaces. This is illustrated in Fig. 7, which is a log-log plot of defect density versus $\left\{N_{\mathrm{av}}-N_{\mathrm{av}}^{*}\right\}^{2}$. The data in this plot include different thin film materials and dielectric interfaces. By including both thin film $a-\mathrm{Si}$ and $a-\mathrm{Si}: \mathrm{H}$, the general trend in Fig. 7 establishes the universality of the approach to interfacial bonding constraints developed in this article.

\section{ACKNOWLEDGMENTS}

Research at NC State University is supported in part by the ONR, the AFOSR, the NSF, the SRC, and SEMATECH.
${ }^{1}$ H. Y. Yang, H. Niimi, and G. Lucovsky, J. Appl. Phys. 83, 2327 (1998). ${ }^{2}$ H. Y. Yang and G. Lucovsky, IEEE Electron Device Lett. (submitted).

${ }^{3}$ Y. Ma, T. Yasuda, and G. Lucovsky, J. Vac. Sci. Technol. A 11, 952 (1993); Y. Ma, T. Yasuda, S. Habermehl, and G. Lucovsky, J. Vac. Sci. Technol. B 11, 1533 (1993); Yi Ma, T. Yasuda, and G. Lucovsky, Appl. Phys. Lett. 64, 2226 (1994).

${ }^{4}$ S. V. Hattangady, H. Niimi, and G. Lucovsky, J. Vac. Sci. Technol. A 14, 3017 (1996).

${ }^{5}$ C. G. Parker, G. Lucovsky, and J. R. Hauser, IEEE Electron Device Lett. 19, 106 (1998).

${ }^{6}$ Y. Wu and G. Lucovsky, IEEE Electron Device Lett. 19, 367 (1998).

${ }^{7}$ V. Misra et al., IEEE Trans. Electron Device (submitted).

${ }^{8}$ B. Y. Kim, H. F. Luan, and D. L. Kwong, Tech. Dig. Int. Electron Devices Meet. 463 (1997).

${ }^{9}$ Y. Shi, X. Wang, and T. P. Ma, IEEE Electron Device Lett. 19, 388 (1998).

${ }^{10}$ Z. Lu, M. J. Williams, P. F. Santos-Filho, and G. Lucovsky, J. Vac. Sci. Technol. A 13, 607 (1995).

${ }^{11}$ G. Lucovsky, Z. Jing, P. Santos-Filho, G. Stevens, and A. Banerjee, J. Non-Cryst. Solids 198-200, 19 (1996)

${ }^{12}$ P. Santos-Filho, G. Stevens, G. Lucovsky, T. Cull, P. Fedders, P. Leopold, and R. Norberg, J. Non-Cryst. Solids 198-200, 77 (1996).

${ }^{13}$ J. C. Phillips, J. Non-Cryst. Solids 34, 153 (1979).

${ }^{14}$ J. C. Phillips, J. Non-Cryst. Solids 47, 203 (1983).

${ }^{15}$ G. Lucovsky and J. C. Phillips, J. Non-Cryst. Solids 227, 1221 (1998).

${ }^{16} \mathrm{~S}$. Campbell, D. Gilmer, X. Wang, M. Hsieh, H. Kim, W. Gladfelter, and J. Yan, IEEE Trans. Electron Devices 44, 104 (1997); X. Guo, T. P. Ma, T. Tamagawa and B. L. Halpern, Tech. Dig. Int. Electron Devices Meet. 377 (1998).

${ }^{17}$ A. Chatterjee et al., Tech. Dig. Int. Electron Devices Meet. 777 (1998).

${ }^{18}$ H. Niimi, H. Y. Yang, and G. Lucovsky, AIP Conf. Proc. 449, 273 (1998).

${ }^{19}$ D. R. Lee, G. Lucovsky, M. R. Denker, and C. Magee, J. Vac. Sci. Technol. A 13, 1671 (1995).

${ }^{20} \mathrm{Y}$ Wu and G. Lucovsky, IEEE Trans. Electron Devices (submitted).

${ }^{21}$ X. Feng, W. J. Bresser, and P. Boolchand, Phys. Rev. Lett. 78, 4422 (1997).

${ }^{22}$ J. E. Huheey, Inorganic Chemistry (Harper and Row, New York, 1978), Chap. 17.

${ }^{23}$ M. Stutzmann, Properties of Amorphous Silicon, 2nd ed. (INSPEC, London, 1989).

${ }^{24}$ J. C. Phillips, in Rigidity Theory and Applications, edited by M. F. Thorpe and P. Duxbury (Michigan State University Press, East Lansing, 1999) (to be published).

${ }^{25}$ J. H. Van der Merwe, J. Appl. Phys. 34, 123 (1963).

${ }^{26}$ S. Y. Ren and J. D. Dow, J. Electron. Mater. 26, 341 (1996).

${ }^{27}$ H. Z. Massoud, Mater. Res. Soc. Symp. Proc. 105, 265 (1988); H. Z. Massoud, J. Appl. Phys. 63, 2000 (1988).

${ }^{28}$ G. Lucovsky and H. Z. Massoud, J. Vac. Sci. Technol. B 16, 2191 (1998).

${ }^{29}$ G. Lucovsky, Y. Wu, H. Niimi, V. Misra, and J. C. Phillips, Appl. Phys. Lett. 74, 2005 (1999).

${ }^{30}$ C. H. Bjorkman, J. T. Fitch, and G. Lucovsky, Appl. Phys. Lett. 56, 1983 (1990).

${ }^{31}$ E. Vogel, P. McLarty, and J. Wortman, IEEE Trans. Electron Devices 43, 753 (1996).

${ }^{32}$ F. L. Galeener, W. Stutius, and G. T. McKinley, in The Physics of MOS Insulators, edited by G. Lucovsky, S. T. Pantelides, and F. L. Galeener (Pergamon, New York, 1980), p. 77.

${ }^{33}$ G. Lucovsky, A. Rozaj-Brvar, and R. F. Davis, in The Structure of NonCrystalline Materials 1982, edited by P. H. Gaskell, J. M. Parker, and E. A. Davis (Taylor and Francis, London, 1983), p. 193. 